\title{
Performance Characteristics of Pine Oil Mixed Diesel Fueled Single Cylinder Four Stroke Diesel Engine
}

\author{
Ishwar Joshi ${ }^{1}$, Surya Prasad Adhikari ${ }^{2, *}$ \\ ${ }^{1}$ Department of Automobile and Mechanical engineering, Institute of Engineering, Thapathali Campus, Nepal \\ ${ }^{2}$ Department of Mechanical and Aerospace Engineering, Institute of Engineering, Pulchowk Campus, Nepal
}

*Corresponding Author: surya@tcioe.edu.np

Received on: $17^{\text {th }}$, Feb., 2021

Accepted for publication: $5^{\text {th }}$, March., 2021

\begin{abstract}
In this study, biodiesel from the stem of Pinus roxburghii was prepared by steam distillation process. Consequently, the physical and thermal properties of pine biodiesel (P100), and $20 \%$ pine-biodiesel and $80 \%$ diesel (P20) were tested on American Society for Testing and Materials (ASTM) standards. The test results confirmed that the thermophysical properties of pine biodiesel and its blend were suitable for the fuel in diesel engine without any modification in the test engine. Eventually, the engine performance and combustion parameters were evaluated for pine-biodiesel blend for $5 \%$ biodiesel and $95 \%$ diesel (P5), $10 \%$ biodiesel and $90 \%$ diesel (P10), $15 \%$ biodiesel and $85 \%$ diesel (P15) and P20, and compared with diesel on Kirloskar Single Cylinder Compression Ignition Engine for a compression ratio of 15:1. In the midst of those in different blends evaluated, P15 showed the better brake specific fuel consumption (BSFC) i.e $18.75 \%$ lower than diesel fuel particularly up to $50 \%$ of the engine load. However, at higher load, decrease rate in BSFC of P15 fuel is lower than engine load up to $50 \%$. Similarly, brake thermal efficiency (BTE) of P15 increases to $13.5 \%$ mainly on $50 \%$ loading condition of the engine. At above, increment rate of BTE of pine oil biodiesel compared to diesel decreases. The brake power (BP) and brake mean effective pressure (BMEP) of P15 also found nearer to diesel. However, the BP of P15 found higher compared to diesel in all loading conditions. Thus, from the experimental investigations, P15 blend of pine oil biodiesel was found to be amenable for its use in compression ignition (CI) engine without any modification, as the BTE and SFC were found to better and, BP, indicated power (IP) and BMEP were also found nearer to diesel fuel.
\end{abstract}

Keywords: Diesel engine, Pine oil, Engine Performance, blended biodiesel.

\section{Introduction:}

In current years, the stipulate for energy is rising day by day. The total principal energy expenditure from crude oil is about $29.45 \%$ [1]. The speedy diminution of crude oil reserves and their unpleasant effects on the environment leads to research curiosity in renewable energy fuels.
The search for the renewable energy source has become more pronounced in recent era.

Biofuel, which is one of the renewable energy fuel produced from biomass, can be important substitute for fossil fuels. Biodiesel, an alternative instead of diesel fuel, is extracted from renewable biological sources such as 
vegetable oils and animal fats. It is environment friendly due its biodegradable and toxic free properties [2]. Methanol and ethanol are two established alternative fuels, which possess the potential substitute of diesel fuel [3]. Biofuel produces more complete combustion than that of conventional diesel fuel due to the additional oxygen content compared to diesel fuel [4].

Normally, plants yields two types of oils, i.e. triglyceride oil (TG oils) and turpene oil (light oil). Among them, triglyceride oil is obtained from plant seeds, whereas turpene oil is obtained from plant parts [5]. Turpene oils are available in some plant species namely eucalyptus, pine tree, etc.[6]. Because of its inherent oxygen content, Pine oil obtained from the pine tree has high calorific value and good solubility, which is comparable to that of diesel fuel [7]. It has been reported that crude plant oils can be used as fuel, either straight or blended with diesel fuel, in diesel engines [8]. Considering these mentioned facts, many researchers have focus their attention to evaluate the performance of $\mathrm{CI}$ engine fuelled with biodiesel blends experimentally varying different parameters.

Hariram V et.al. studied on the influence of compression ratio on combustion and performance characteristics of direct injection compression ignition engine. Their studied concluded that BSFC and exhaust gas temperature were increased on reducing the compression ratio. However, BTE was decreased on reducing the compression ratio [9]. Tamilselvan $\mathrm{P}$ et.al. conducted their research using pine oil of Pinus sylvestris species experimentally and evaluated the performance of $\mathrm{CI}$ engine. Their results showed that the BTE was slightly higher than diesel fuel due to the improved automization, fuel vaporization and combustion of less viscous fuels. However, BSFC was somewhat lower compared to that of diesel fuel because of the combined effect of lower viscosity and higher calorific value [10]. Similarly, Nallusamy D and his team studied the performance and emission characteristics of a single cylinder direct injection diesel engine using an alternative fuel of the biofuel mixed with pine oil and its blends. Their experimental results showed that the $5 \%$ of pine oil had significantly comparable BTE and BSFC of diesel fuel. Consequently, their results also illustrated that the $\mathrm{HC}$ and $\mathrm{CO}$ emissions level have been considerably reduced for pine oil compared with regular diesel at advanced loading conditions. On the other hand, pine oil shows an advanced level of NOX emission compared to normal diesel [11]. In the same way, Huang $\mathrm{H}$ et.al. studied the combustion performance and emission characteristics of a diesel engine under low-temperature combsution of pine oil-diesel blends. Their experimental results showed that the equivalent BSFC of all blended fuel were slightly higher than that of pure diesel. However, BSFC of 50\% diesel and $50 \%$ pine oil blend fuel had only $2.08 \%$ to $3.5 \%$ higher than pure pine oil [12]. Hakk1 M et.al. focused their study on the effect of turpentine oil blended with gasoline, diesel and gasoline-like distilled engine oil on the engine performance and exhaust emissions. From their study, they illustrated that turpentine oil had a positive influence on engine performance and exhaust emissions [13].

Likewise Raman V studied on combustion performance and emission characteristics from a diesel engine fueled by pine oil biofuel using selective catalytic reduction (SCR) and catalytic converter. From their experimental study they observed that the BTE increased as the composition pine oil increase in the blend and the major emissions such as smoke, carbon monoxide (CO) and hydrocarbon (HC) were reduced by $70.1 \%, 67.5 \%$ and $58.6 \%$ respectively, than diesel [14]. Thus, the above mentioned investigations described the engine performance and emission characteristics of the diesel engine fuelled with different biodiesel blends. Here, our main aim of the study is to produce pine oil from the locally available resources and study the performance and emission characteristics of a single cylinder, constant speed direct injection diesel using those oil blends as an alternative fuel without any modifications of the engine.

\section{Experimental Methods and Materials:}

\subsection{Pine Oil Biodiesel-an Overview:}

Due to its comparable properties, pine oil, a renewable biomass source of fuel can be blended with petroleum- based diesel fuel [15]. Pinus roxburghii sarg is a species of several evergreen trees belonging to the Pinaceae and is inhabitant 
to the Himalayas and dispersedall through Pakistan, India, Nepal and Bhutan [16].The reports find that around 105 species are estimated worldwide[17]. However, only 3 Pinus species i.e. P.roxburghii, P. wallichiana, and $P$. wallichiana var. manangens is are found in Nepal[18]. P. roxburghii is a large tree attaining upto $28-55 \mathrm{~m}$ in height with a trunk diameter reaching upto $2 \mathrm{~m}[19]$. The cones of $\mathrm{P}$. roxburghii are ovoid conic and usually open upto $20 \mathrm{~cm}$ to release seed. Pine oil is a nonedible oil obtained from the needles, twigs and cones from a variety of species of pine, particularly Pinus roxburghii of the Pinaceae family using steam distillation method.

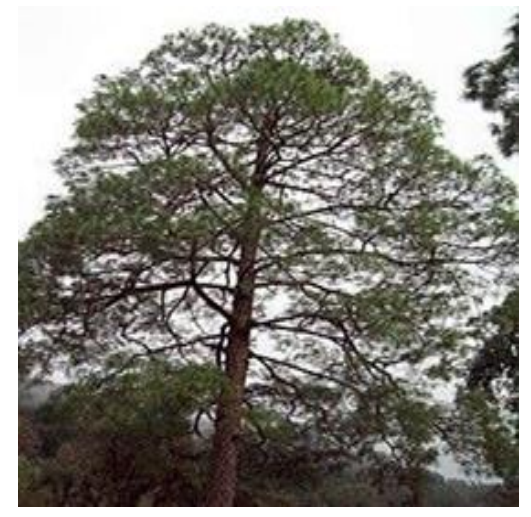

Figure 1: Pinus Roxburghii

\subsection{Composition of Pine Oil:}

Methyl esters, the final product of transesterification reaction by $20 \%$ of volume and diesel by $80 \%$ of volume was mixed by measuring with measuring cylinder for characterization of biodiesel blends.

Pine oil is pale yellow in color having a fresh forest smell, alcoholic compounds and watery in viscosity. It is obtained from oleoresin of pine tree and contains terpineol, which is a tertiary alcohol, along with pinene [20]. Theoleoresin (turpentine oil), is extracted from the leaves, bark of Pinus roxburghii (local name: Khote Sallo). The chief active chemical ingredients of turpentine oil from Pinus roxburghii Sarg are $\alpha$ pinene, $\beta$-pinene, car-3-ene and longifolene [21].

\subsection{1. $\alpha$-Pinene:}

$\alpha$-Pinene is an organic compound of the terpene class, one of two isomers of pinene [3]. It is an alkene and it contains a reactive four-membered ring. It is found in the oils of many species of many coniferous trees, notably the pine [22].

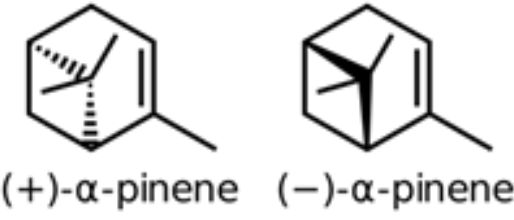

Figure 2: Alpha-pinene

\subsection{2. $\beta$-pinene:}

Beta-pinene ( $\beta$-pinene) is a monoterpene, an organic compound found in plants. It is one of the two isomers of pinene, the other being $\alpha$ pinene. It is colorless liquid soluble in alcohol, but not water. It has a woody-green pine-like smell [23].

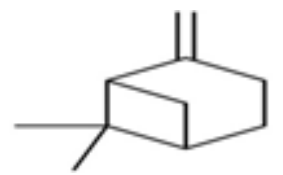

Figure 3: Beta-pinene

\subsubsection{Car-3-ene:}

Car-3-ene is a car-3-ene (3,7,7-trimethylbicyclo [4.1.0] hept-3-ene) that has $\mathrm{S}$ configuration at position 1 and $\mathrm{R}$ configuration at position 6 . It is an enantiomer of a (-)-car-3-ene[24].

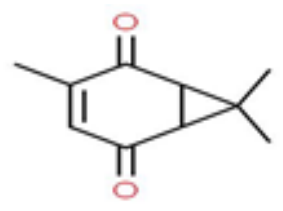

Figure 4: Car-3-ene

\subsection{Preparation of Pine Oil Biodiesel:}

For the extraction of essential oil, the resin was collected from Pinus roxburghii plant.

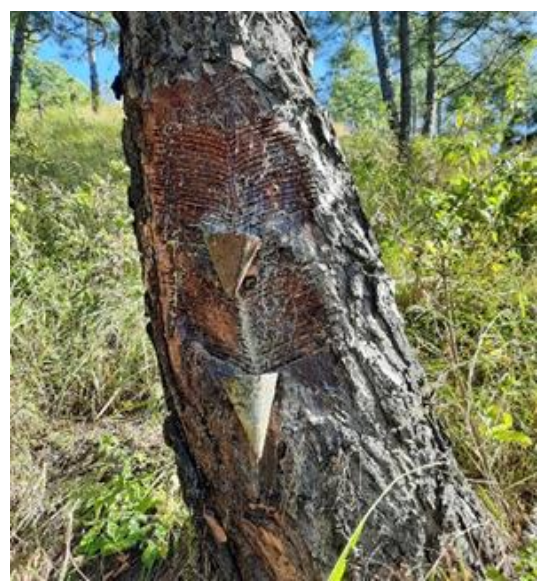

Figure 5: Resin Collection 
The resin was collected from Dadeldhura district of Nepal. The Pinus roxburghii plant was identified by agriculture specialist. The collected resin was then subjected to steam distillation process at about $150{ }^{\circ} \mathrm{C}$. After steam distillation the resin converts into rosin (solid), turpentine oil (liquid) and waste which include water vapor, inert material etc.

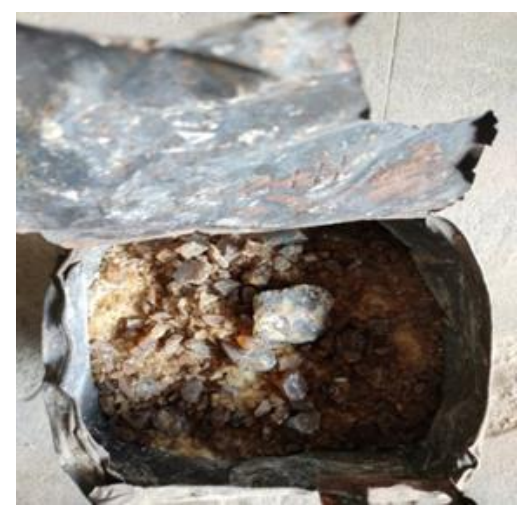

Figure 6: Rosin

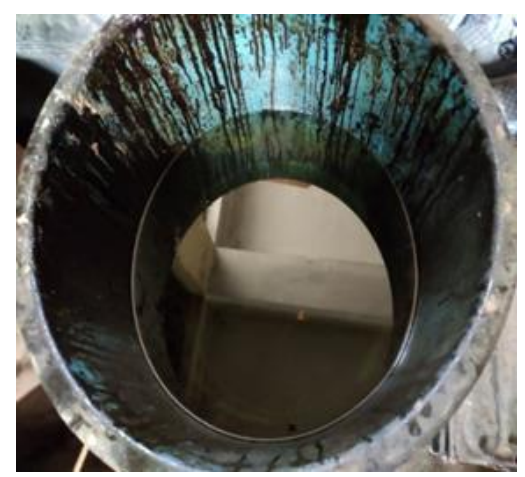

Figure 7: Turpentine Oil

\subsection{Preparation of Pine Oil Blends:}

Different pine oil blends with diesel such as P5, P10, P15 and P20 were prepared in laboratory of Thapathali campus. These blends were used in the research engine to study the performance of the engine at various loading condition of $1,3,6$, 9 and $12 \mathrm{~kg}$.

\subsection{Thermo-physical Properties Test of Blended Pine Oil Biodiesel Fuel:}

Different fuel properties like density, viscosity, kinematic viscosity, calorific value and various other properties were tested for turpentine and P20 at "Unit-2" (D-18, Infocity Phase-II, Sector33) of FARE Lab Delhi, India.

\subsection{Engine Specifications:}

The research was conducted in the Automobile lab of Thapathali Campus . The test engine was Kirloskar Direct Injection Research Diesel Engine which is single cylinder four stroke constant speed water cooled engine. The engine is designed to produce power of $3.5 \mathrm{~kW}$ at rated speed of $1500 \mathrm{rpm}$. The technical specification of research engine is shown in Table 1.

\begin{tabular}{cc}
\multicolumn{2}{c}{ Table 1: Engine Specification } \\
\hline Engine & Kirloskar \\
Type & $\begin{array}{c}\text { Single Cylinder, Four stroke, } \\
\text { Constant Speed, Water } \\
\text { Cooled Diesel Engine }\end{array}$ \\
$\begin{array}{c}\text { Rated power } \\
\text { Rated speed } \\
\text { Cylinder } \\
\text { Bore }\end{array}$ & $1500 \mathrm{~kW}$ \\
$\begin{array}{c}\text { Stroke length } \\
\text { Compression } \\
\text { ratio }\end{array}$ & $87.5 \mathrm{~mm}$ \\
Swept \\
volume
\end{tabular}

The figure 8 shows the required setup research engine.

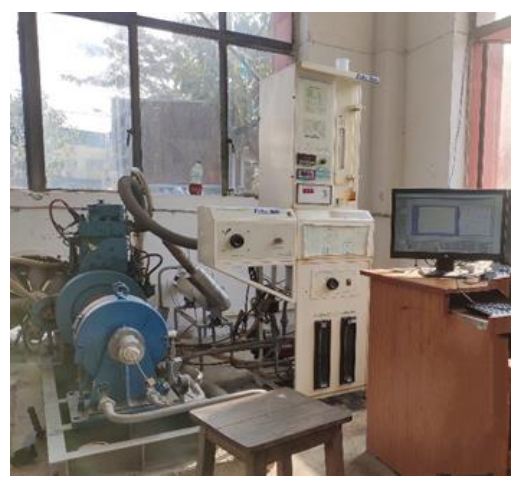

Figure 8: Test Engine Setup

\subsection{Experimental Test Procedure:}

Initially, research engine was tested on a compression ratio of $15: 1$, with diesel fuel at a steady speed of $1500 \mathrm{rpm}$ for 15 to 20 minutes to attain stable working environment. During testing, engine coolant water should be circulated in the engine at a pressure of nearly $1 \mathrm{~atm}$. This can be checked by the pressure gauge setup in the engine. After that, engine was run with P5, P10, P15 and P20 as-prepared pine oil biodiesel blends. Throughout the test, an eddy current dynamometer was used to vary the applied load. The $1-12 \mathrm{~kg}$ load was at an interval of $3 \mathrm{~kg}$ i.e. $1 \mathrm{~kg}, 3 \mathrm{~kg}, 6 \mathrm{~kg} 9 \mathrm{~kg}$ and $12 \mathrm{~kg}$ at a constant speed of $1500 \mathrm{rpm}$ and the required 
engine performance data for different blends were taken. Correspondingly, same procedures were followed for diesel fuel to take the required data for comparison. The rate of flow of biodiesel fuel is measured using a burette and stop watch setup in the engine where fuel consumed during $60 \mathrm{sec}$ time is noted.

\section{Result and Discussion:}

\subsection{Thermo-physical Properties of Diesel and Biodiesel Blended Fuel:}

The blended biodiesel prepared in the lab was tested in Fare Lab - Food Analysis and Research Laboratory, Gurgaon 1220002, India, as per the test method of ASTM standards. The obtained values of the test are shown in Table 2. These acquired numerical values of those physicalchemical properties of blended fuel were comparable to diesel.

Table 2: Properties of Diesel, P100 and P20

\begin{tabular}{|c|c|c|c|c|}
\hline $\begin{array}{c}\text { S. } \\
\text { No. }\end{array}$ & Parameters & Diesel & P100 & P20 \\
\hline 1 & $\begin{array}{c}\text { Pour Point, } \\
{ }^{\circ} \mathrm{C}\end{array}$ & -25 & $\begin{array}{l}\text { Less } \\
\text { than } \\
-33\end{array}$ & -10 \\
\hline 2 & $\begin{array}{c}\text { Flash Point, } \\
{ }^{\circ} \mathrm{C}\end{array}$ & 57 & 45 & 42 \\
\hline 3 & $\begin{array}{l}\text { Kinematic } \\
\text { Viscosity } \\
@ 40^{\circ} \mathrm{C}, \mathrm{cSt}\end{array}$ & 5 & 2.33 & 2.268 \\
\hline 4 & $\begin{array}{c}\text { Density@15 } \\
{ }^{\circ} \mathrm{C}, \mathrm{kg} / \mathrm{m} 3\end{array}$ & 853 & 842 & 840 \\
\hline 5 & $\begin{array}{c}\text { Calorific } \\
\text { Value, } \\
\text { Kcal/kg }\end{array}$ & 11110 & 11602 & 11214 \\
\hline
\end{tabular}

\subsection{Engine Performance Results:}

The performance of the CI engine depends on various parameters, such as injection pressure, combustion duration, mixing of fuel with air, inlet temperature of the air, ignition delay and fuel properties like viscosity, calorific value, flash point, pour point, density, cetane number etc. Here, in this study, experiment was carried out to estimate the engine key performance parameter like Specific Fuel Consumption (SFC), Brake Power (BP), Brake Thermal Efficiency (BTE), Brake Mean Effective pressure (BMEP) of a CI engine using pine oil blends fuel. The obtained results were compared with diesel fuel and different on values on both conditions were discussed based on the properties of both diesel and pine oil blended fuels. For each pine oil blends and diesel two set of readings were observed and the average value was then taken for consideration.

\subsubsection{Specific Fuel Consumption (SFC):}

The variation of SFC with different loading condition for diesel fuel and pine oil blends is presented in figure 9. For diesel and pine oil blends, SFC is found to decrease with increase in load. For all pine oil blends the SFC is lower than that of the diesel fuel at all load. The obtained results are in accordance with the results obtained by Vignesh3 et.al. [25]. When compared with diesel, SFC of pine oil biodiesel blend decreases. The lower kinematic viscosities compared to that of diesel fuel result in better atomization and disperse of fuel in the combustion chamber, which helps to accomplish a faster and more complete combustion [11]. At higher load conditions, SFC decreases compared to diesel. This is due to lower viscosity and high calorific value of pine oil and its blends. At 1, 6, and $9 \mathrm{~kg}$ load, P15 has lower value of SFC which are $1.40,0.42,0.43 \mathrm{~kg} / \mathrm{kWh}$ and diesel fuel has 1.98, 0.49 and $0.44 \mathrm{~kg} / \mathrm{kWh}$ at respective loading condition. At maximum load of $12 \mathrm{~kg}, \mathrm{P} 10$ has minimum value of 0.43 $\mathrm{kg} / \mathrm{kWh}$ and for diesel at same load SFC was found to be $0.57 \mathrm{~kg} / \mathrm{kWh}$.

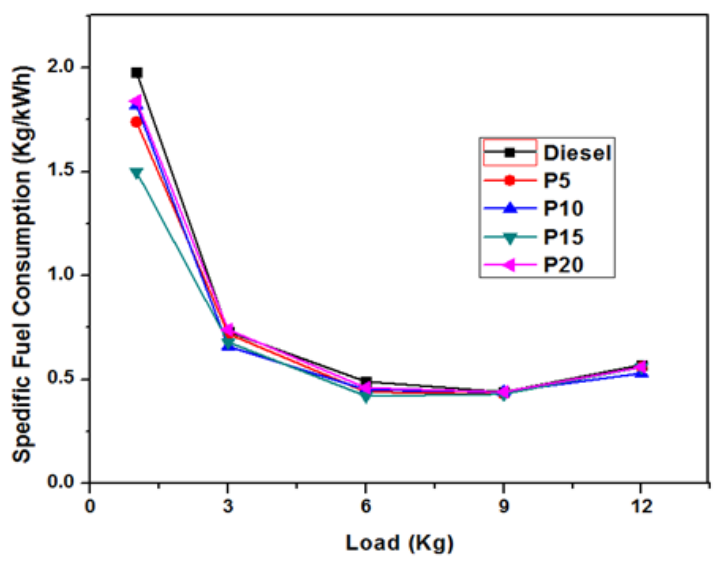

Figure 9: Load Vs Specific Fuel Consumption

\subsubsection{Brake Thermal efficiency (BTE):}

The variation of BTE with load for diesel and various pine oil blends is shown in Fig. 10. Mostly in all cases, BTE has the tendency to increase with increase in load, this is due to reduction in heat loss and increase in power developed with increase in load [26]. It is well 
understood that BTE depends on total fuel consumption i.e., inversely proportional to each other. Since pine oil blends have equivalent calorific value towards diesel, at higher load conditions pine oil blends shows improved efficiency [25].

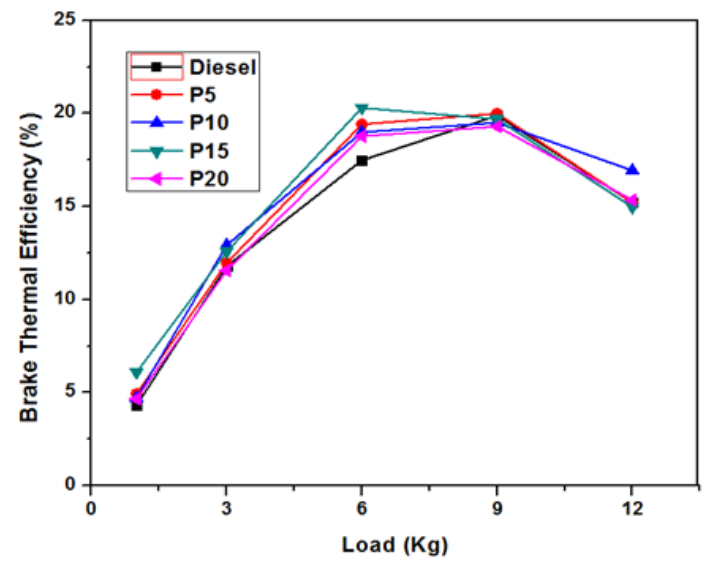

Figure 10: Load Vs Brake Thermal Efficiency

BTE is raised considerably up to $50 \%$ of the load in all blends. Among all blends, P15 has shown better BTE. However, at higher loading conditions, the rate of increment of BTE for all blends is reduced. Here, BTE of P15 increases to $13.5 \%$ mainly on $50 \%$ loading condition of the engine. This is mainly due to the combined effect of lower viscosity and higher calorific value [27]. In addition, shorter ignition delay duration associated with deficiency of oxygen led to the possibility of partial combustion at full load condition resulting drop in engine performance $[28,29]$. In this study, it is also evident that at high load, BTE drops and at 12 $\mathrm{kg}$ load, P10 has maximum value and BTE increases by $4.72 \%$ compared to that of diesel.

\subsubsection{Indicated Power (IP)}

Figure 11 illustrated that the Indicated Power (IP) increases with load in diesel and all pine oil blends. P15 shows comparable indicated power at all load with that of diesel fuel. Here, IP for all blends and diesel increases with engine load. ignition delay for all fuels decreases as the engine load increases because the gas temperature inside the cylinder is higher at high engine load. thus, it reduces physical ignition delay, which increases IP [30]. At low and high loading condition of $1 \mathrm{~kg}$ and $12 \mathrm{~kg}, \mathrm{P} 10$ has higher value of $2.13 \mathrm{KW}$ and $4.48 \mathrm{KW}$, whereas the indicated power for diesel at respective loading condition was found to be $1.95 \mathrm{~kW}$ and $4.29 \mathrm{~kW}$ respectively. Similarly, brake power of P15 at all loading conditions were also found higher than diesel. The probable reason may be affirmed as, increase in IP leads to better automization of fuel, enhanced spray characteristics and condensed physical delay period, which improved premixed combustion and rapid combustion rate [31]. This is due to the higher calorific value and lower kinematic viscosity of the pine oil and pine-biodiesel blended oils.

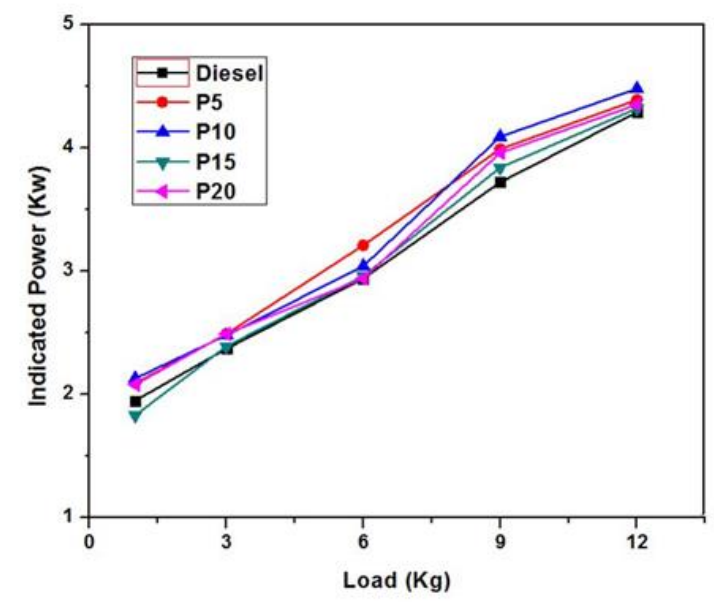

Figure 11: Load Vs Indicated Power

\subsubsection{Brake Power (BP):}

Figure 12 illustrates the variation of $\mathrm{BP}$ with load for diesel and all pine oil blends. The value of BP increases with increase in load in all cases. This designates lower frictional loss at high loads when compared to low loads. P10 has higher value of BP than diesel fuel at all loading condition.

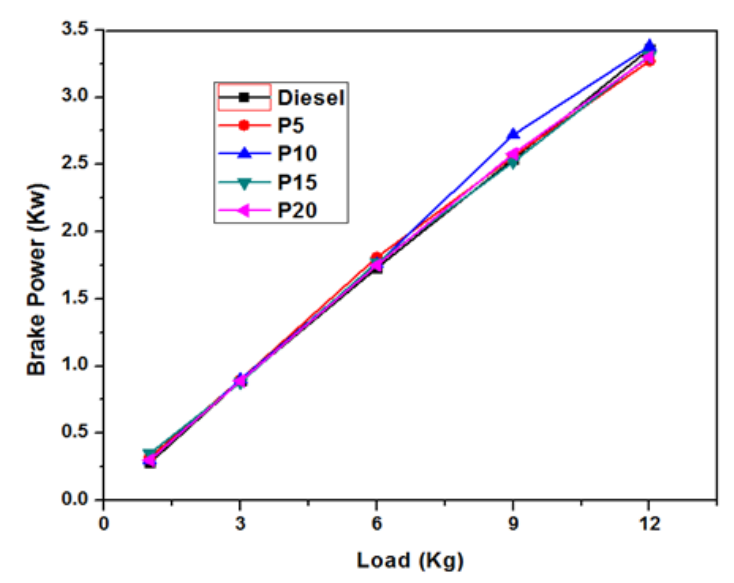

Figure 12: Load Vs Brake Power 
At $1 \mathrm{~kg}$ and $12 \mathrm{~kg}$ loading condition the value of BP for P10 was found to be $0.30 \mathrm{~kW}$ and 3.38 $\mathrm{kW}$, respectively, and at respective loading condition for diesel the value of $\mathrm{BP}$ was 0.28 and $3.36 \mathrm{~kW}$.

\subsubsection{Brake Mean Effective pressure (BMEP):}

The variation of BMEP for diesel and various pine oil blends is illustrated in Fig. 13. In all cases BMEP increases with increase in load. Pine oil blends shows similar BMEP at all loading condition compared with diesel fuel. Here, BMEP of P15 and P10 at all loading conditions are better than P20 and diesel fuel.

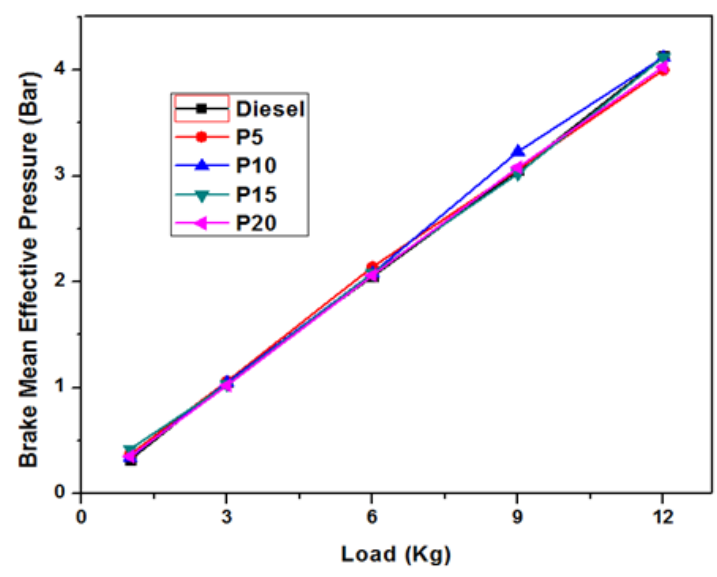

Figure 13: Load Vs Brake Mean Effective Pressure

\subsubsection{Mechanical Efficiency (ME):}

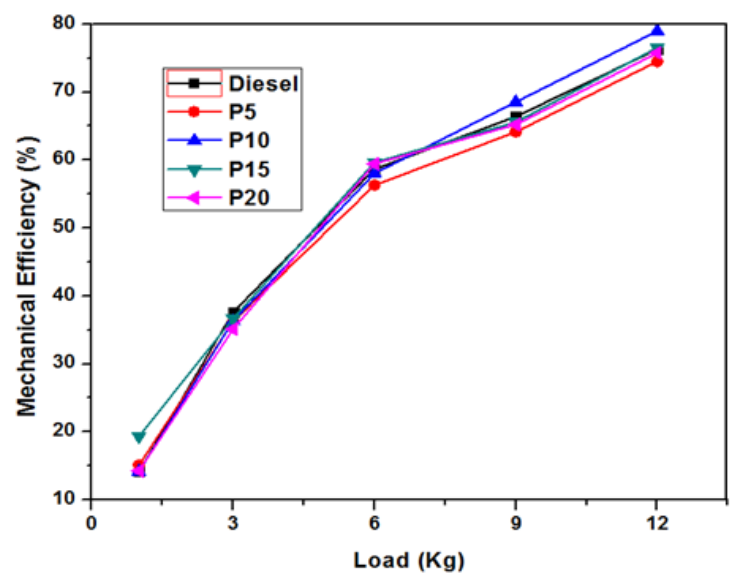

Figure 14: Load Vs Mechanical Efficiency

Figure 14 shows Mechanical Efficiency (ME) of diesel and different pine oil blends. Here, the ME increases with increase in load for various pine oil blends and diesel fuel. With increasing load, frictional losses decrease and mechanical efficiencies increase [32]. The ME for the blend is higher than the diesel fuel due to higher calorific value of pine oil. At higher loading condition of $12 \mathrm{~kg}$ it was found that P10 has ME of $78.97 \%$, and ME increases for P10 by $2.68 \%$ compared to that of diesel fuel at respective loading condition.

Thus, the above obtained experimental results confirmed that the increment in BTE and reduction in SFC made the blends of pine oil biodiesel a suitable alternative fuel for diesel. Moreover, among all blends, P15 showed better engine performance at average loading condition, but at higher loading condition for same compression ratio, P10 showed better performance. These variation on the blends might be likely due to the difference in the actual thermo-physical properties between the various blend ratio. Similarly, reduction of SFC and, increment BTE and ME of biodiesel blends obtained in this study were higher compared to the past research literature $[9,10,33,34]$.

\section{Conclusion:}

From experimental investigation following conclusion can be drawn;

a. Specific fuel consumption of P15 at lower loading condition of $1 \mathrm{~kg}$ decreases by 0.58 $\mathrm{kg} / \mathrm{kWh}$ and at higher loading condition of $12 \mathrm{~kg}$ SFC of P10 reduced by $0.14 \mathrm{~kg} / \mathrm{kWh}$ compared to that of the diesel fuel, this is due to lower viscosity and high calorific value of pine oil and its blends

b. At $50 \%$ loading condition i.e. up to $6 \mathrm{~kg}$, P15 shows higher BTE and lower SFC. However, decrement rate of SFC and increment rate of BTE of pine oil blended biodiesel compared to diesel reduced at higher load i.e. at $9 \mathrm{~kg}$ and $12 \mathrm{~kg}$. Moreover, BP, IP and BMEP of P15 also obtained comparable to diesel fuel.

c. The IP and BP for P10 were found to be higher than that of other blend and diesel fuel at all loading condition.

d. The ME for pine oil blend was found to be higher than that of diesel fuel due to higher calorific value of pine oil. At all loading conditions, the ME of all blended fuels were found comparable to that of diesel fuel. 
Thus the experimental results prove that the use of pine oil blends in CI engine is a viable alternative to diesel.

\section{Acknowledgements:}

This project was supported by the University Grant Commission, Nepal, through Master Research Support (MRS-76177- Engg-6). We would like to thank the staff of Department of forest and soil conservation (DOFSE), Nepal. I am indebted to Er. Laxman Palikhel, for his continuous support during experimental work and afterward.

\section{References:}

[1] Shirneshan A. HC, CO, CO2 and NOx Emission Evaluation of a Diesel Engine Fueled with Waste Frying Oil Methyl Ester. Procedia - Social and Behavioral Sciences 2013;75:292-7.

[2] Demirbaş A. Biodiesel: A Realistic Fuel Alternative for Diesel Engines 2008.

[3] Purushothaman K NG. Performance, emission and emission and combustion characteristics of a compression ignition engine operating on neat orange oil. Renewable energy 2009.

[4] PremAnand B SC, Ananda Srinivasan C. Performance and exhaust emission of turpentine oil powered direct injection diesel engine. Renewable Energy 2010.

[5] Chankarasekharendra S, Viswa S. A Performance, Emission and Combustion Investigation on Hot Air Assisted Eucalyptus Oil Direct Injected Compression Ignition Engine. 2011.

[6] Tamilvendhan D IV. A performance, emission and combustion investigation on hot air assisted eucalyptus oil direct injected compression ignition engine. 2011:53_62.

[7] Raman V, Sivasankaralingam V, Yang WM, Saravanan C, Lee PS, Chua KJ, et al. Impact of pine oil biofuel fumigation on gaseous emissions from a diesel engine. Fuel Processing Technology 2014;124:44-53.

[8] Blin J, Brunschwig C, Chapuis A, Changotade O, Sidibe SS, Noumi ES, et al. Characteristics of vegetable oils for use as fuel in stationary diesel enginesTowards specifications for a standard in West Africa. Renewable and Sustainable Energy Reviews 2013;22:580-97.

[9] Hariram V, Vagesh Shangar R. Influence of compression ratio on combustion and performance characteristics of direct injection compression ignition engine. Alexandria Engineering Journal 2015;54:807-14.

[10] Tamilselvan P, Nallusamy N. Performance, combustion and emission characteristics of a compression ignition engine operating on pine oil. Biofuels 2015;6:273-81.

[11] Nallusamy D, Sendilvelan S, Bhaskar K, $\mathrm{N}$ M. Analysis of performance, combustion and emission characteristics on biofuel of novel pine oil. Rasayan Journal of Chemistry 2017;10:873-80.

[12] Huang H, Teng W, Liu Q, Zhou C, Wang Q, Wang X. Combustion performance and emission characteristics of a diesel engine under low-temperature combustion of pine oil-diesel blends. Energy Conversion and Management 2016;128.

[13] Hakk1 M, Salan T. A Review on Novel Bio-Fuel from Turpentine Oil. Processes of Petrochemistry and Oil Refining 2017;18:1-12.

[14] Raman V, Sivasankaralingam V, Yang WM, Saravanan C, Lee PS, Chua KJ, et al. Emission reduction from a diesel engine fueled by pine oil biofuel using SCR and catalytic converter. Atmospheric Environment 2013;80:1907.

[15] Raman V, Sivasankaralingam V, Yang WM, Lee PS, Chua KJ, Chou SK. Pine oil-biodiesel blends: A double biofuel strategy to completely eliminate the use 
of diesel in a diesel engine. Applied Energy 2013;130.

[16] Satyal P, Paudel P, Raut J, Deo A, Dosoky NS, Setzer WN. Volatile constituents of Pinus roxburghii from Nepal. Pharmacognosy Res 2013;5:438 .

[17] Farjon A. Pines: drawings and descriptions of the genus Pinus Leiden, The Netherland Brill; 2005.

[18] J.R S, K.K \& Sutton, DA. Annoted Checklist of the flowering Plants of Nepal. 2000.

[19] 1998. CSg. Pinus roxburghii. In IUCN 2011.

[20] Vallinayagam R, Vedharaj S, Yang WM, Saravanan CG, Lee PS, Chua KJE, et al. Emission reduction from a diesel engine fueled by pine oil biofuel using SCR and catalytic converter. Atmos Environ 2013;80:190-7.

[21] Smaleh M SO, Dobhal NP. Chemical composition of turpentine oil from oleoresin tapped by chemical stimulant. Indian Perfumer 1976:15-9.

[22] Simonsen PJL. The terpenes Journal of the society of Chemical Industry 1957:105-91.

[23] Vespermann KAC, Paulino BN, Barcelos MCS, Pessôa MG, Pastore GM, Molina G. Biotransformation of $\alpha$ and $\beta$-pinene into flavor compounds. Appl Microbiol Biotechnol 2017;101:1805-17.

[24] Grebner DL, Bettinger P, Siry JP, Boston K. Chapter 1 - A brief history of forestry and natural resource management. In: Grebner DL, Bettinger P, Siry JP, Boston K, editors. Introduction to Forestry and Natural Resources (Second Edition). San Diego: Academic Press; 2022. p. 1-19.

[25] Vignesh3 DKSAPSBMSJ. Performance and Emission Characteristics of Diesel Engine Using Pine. IJSRD International Journal for Scientific
Research \& Development Vol. 5, Issue 03, 2017.

[26] Nedayali A, Shirneshan A. Experimental Study of the Effects of Biodiesel on the Performance of a Diesel Power Generator. Energy \& Environment 2016;27:553-65.

[27] P T, Nallusamy N. Performance, combustion and emission characteristics of a compression ignition engine operating on pine oil. Biofuels 2015;6:19.

[28] D. Babu RA. Chapter 14 - Biodieseldiesel-alcohol blend as an alternative fuel for DICI diesel engine,. 11 July 2019:Pages 337-67,

[29] Babu D, Anand R. Chapter 14 Biodiesel-diesel-alcohol blend as an alternative fuel for DICI diesel engine. In: Azad AK, Rasul M, editors. Advanced Biofuels: Woodhead Publishing; 2019. p. 337-67.

[30] Yesilyurt MK, Yilbasi Z, Aydin M. The performance, emissions, and combustion characteristics of an unmodified diesel engine running on the ternary blends of pentanol/safflower oil biodiesel/diesel fuel. Journal of Thermal Analysis and Calorimetry 2020;140:2903-42.

[31] Mahendran M, Rathinasamy T, Prakash R. Effect of Single And Three Hole Fuel Injector Nozzle on Performance And Emission Characteristic of Diesel on A Vcr Engine. JOURNAL OF APPLIED SCIENCES RESEARCH 2016;11:93-9.

[32] Rahman SMA, Nabi MN, Van TC, Suara K, Jafari M, Dowell A, et al. Performance and Combustion Characteristics Analysis of MultiCylinder CI Engine Using Essential Oil Blends. Energies 2018;11:738.

[33] Kumar JK, Raj CS, Sathishkumar P, Gopal P, Antony A. Investigation of Performance and Emission Characteristics of Diesel Blends with Pine Oil. Journal of Applied Fluid Mechanics 2018;11:63-7. 
Himalayan Journal of Applied Science and Engineering (HiJASE), Vol. 2, Issue 1, No. 6, 2021

[34] Rahman SMA, Nabi M, Chu Van T,

Characteristics Analysis of MultiSuara K, Jafari M, Dowell A, et al. Cylinder CI Engine Using Essential Oil

Performance and

Combustion Blends. Energies 2018;11:738. 